\title{
Differentiating Normal Newborn Weight Loss From Breastfeeding Failure
}

Share this: f

Catherine Watson Genna, BS, IBCLC, RLC Micaela Notarangelo, PhD, IBCLC, RLC ${ }^{b}$

There is increasing concern for the risk of hypernatremic dehydration in infants breastfeeding poorly. It is important to differentiate normal weight changes as infants adapt to extrauterine life from excessive weight loss from breastfeeding failure or mismanagement. We review recent data on normal weight changes in exclusively breastfeeding infants and those at risk for hypernatremic dehydration to help health professionals determine when infants require further scrutiny and supplementation. The data suggest that perinatal practices influence infant weight changes. Protecting normal birth and early initiation of breastfeeding should reduce the incidence of excessive weight loss and risk of hypernatremic dehydration

Keywords: growth nomograms; weight loss; breastfeeding; hypernatremic dehydration; birth interventions

Newborns are expected to lose weight in the first few days after birth, as part of healthy adaptation to extrauterine life (DeMarzo, Seacat, \& Neifert, 1991; Mulder \& Gardner, 2015; Tawia \& McGuire, 2014) and promptly begin gaining as milk production increases. Colostrum volume is low initially and milk production should increase rapidly over the first 72 hours of life (Neville et al., 1988).'

Breastfeeding difficulties (infant, maternal, or dyadic, environmental or management related) can exaggerate normal weight loss (Dewey, Nommsen-Rivers, Heinig, \& Cohen, 2003; Mulder, Johnson, \& Baker, 2010). Frequent or daily weighing in the first 5 to 7 days has been proposed to reduce the risk of hypernatremic dehydration (HDN) (Iyer et al., 2008; Konetzny, Bucher, $\&$ Arlettaz, 2009). It can be challenging to differentiate normal weight loss from excessive loss that might signal lactation failure (Verd, de Sotto, Fernández, \& Gutiérrez, 2018). Understanding the data we have about weight loss, and carefully assessing the breastfeeding dyad, can help prevent hypernatremic dehydration and conversely, unnecessary formula supplementation. Unnecessary supplementation impairs the infant's microbiota (Timmerman et al., 2017) and reduces breastfeeding success (Chantry, Dewey, Peerson, Wagner, \& Nommsen-Rivers, 2014). More research is needed on the impact of excessive infant weight loss on continuation and long-term exclusivity of breastfeeding. Dyads with excessive early weight loss seem less likely to return to exclusive breastfeeding (Flaherman et al., 2017).

a. cwgenna@gmail.com

b. micaelanotarangelo@gmail.com

\section{Strategies to Protect Infants From Hypernatremic Dehydration}

Several strategies have been successful in protecting infants from hypernatremic dehydration while simultaneously protecting breastfeeding. The most effective programs modulate their intervention according to the level of weight loss.

- For infants who have lost $7 \%$ to $8 \%$ of birth weight, strategies included monitoring weight every 24 hours, providing breastfeeding support and assistance, and supplementing with expressed colostrum or milk if milk transfer at breast is poor.

- For infants who lost more than $10 \%$, the first step is supplementation with expressed milk, then checking blood sodium levels, and rehydration and more intense supplementation if hypernatremia is identified.

- Infants displaying symptoms of dehydration are assessed and treated promptly (Davanzo, Cannioto, Ronfani, Monasta, \& Demarini, 2013; Manganaro, Mamì, Marrone, Marseglia, \& Gemelli, 2001).

\section{The Impact of Birth Interventions and Hospital Routines}

Birth interventions and hospital routines affect breastfeeding opportunities and impact weight changes in newborns. Increased urination was associated with greater weight loss in the first 48 hours in successfully breastfeeding newborns (Mulder et al., 2010). Excessive intravenous fluids during labor and delivery may lead to increased weight loss in the first 24 hours of life as 
the infant urinates to restore normal fluid balance (Noel-Weiss, Woodend, Peterson, Gibb, \& Groll, 2011). Infants born by cesarean lost more weight and were more vulnerable to hypernatremic dehydration (HDN) (Jain \& Basu, 2010).

Tracking weight loss from the 24-hour weight (instead of birth weight) in infants born by cesarean in a BabyFriendly hospital reduced supplementation without an increase in hypernatremic dehydration and rehospitalization (Deng \& McLaren, 2018). In a retrospective chart review, infants who lost the most weight their first day $(>4.5 \%)$ were 3.5 times more likely to lose $>10 \%$ of birthweight during their hospitalization (Flaherman et al., 2015). Flaherman et al. (2013) caution against diminishing maternal confidence in breastfeeding when this occurs.

\section{Normal Versus Problematic Weight Loss}

Commonly accepted values for normal newborn weight loss (7\%) and problematic weight loss (10\%) are based on a small number of data points per infant (DeMarzo et al., 1991). A systematic review by NoelWeiss, Courant, and Woodend (2008) stresses that the weight loss data published up to that time were mainly median values derived from different populations with different methodologies. The great variability of individuals and environmental inputs makes it difficult to interpret any single infant's weight changes. It would be like buying t-shirts for a large public event, and only ordering size medium: some participants will be stuck with a shirt that is too small, and others with one that is too large. Similarly, attending only to median values gets some infants too much intervention, and others not enough.

The age of the infant at each weight is a vital variable. Earlier studies have followed healthy, exclusively breastfed newborn infants and tracked their weight nadir and time to regain birthweight using few measurements spread over several weeks (DeMarzo et al., 1991; Macdonald, Ross, Grant, \& Young, 2003). Frequent measurements provide better information about the pattern and timing of weight changes in breastfeeding infants (Crossland, Richmond, Hudson, Smith, \& AbuHarb, 2008; Grossman, Chaudhuri, Feldman-Winter, \& Merewood, 2012).

\section{Identifying Babies at Risk}

Nomograms are charts that help capture the time dimension and individual variations to help determine whether babies are progressing normally or are at risk. Several groups have produced nomograms that clinicians can use to help screen newborns (Table 1). van Dommelen and colleagues (van Dommelen, van Wouwe, BreuningBoers, van Buuren, \& Verkerk, 2007) used statistical analysis of weight changes in large cohorts of exclusively breastfed infants from day 2 through 11 to construct normal growth curves, and compared them to those from two groups of infants with hypernatremic dehydration. They were able to see that infants who developed HND had already lost significantly more weight than infants who did not long before showing symptoms. The group then produced a nomogram that predicts elevated risk of hypernatremic dehydration in the first week of life, so it can be prevented by breastfeeding assistance and stimulation of maternal milk production.

Bertini and colleagues used 12 hourly measurements in a Baby-Friendly birth center environment to extract normal growth patterns of exclusively breastfed infants (Bertini et al., 2015). Other groups used complex statistical techniques that pair the age of infants at a smaller number of measurements versus their birthweights to construct nomograms (Flaherman et al., 2015; Fonseca et al., 2015; van Dommelen et al., 2014) or prediction tools (Wilbaux et al., 2016). Figure 1 compares the $50^{\circ}$ percentile line of the nomograms created by different authors (Bertini et al., 2015; Flaherman et al., 2015; Fonseca et al., 2015; van Dommelen et al., 2014). It is important to note that the sample size in Bertini et al. (2015) is different at different points of time. By 72 hours, only a small number of infants remained, and it is possible that more slower growing infants were over-represented, so data from that time point are less reliable.

\section{Factors Related to Risk}

Nomograms developed by different studies point up some of the factors that support or interfere with breastfeeding initiation. Infants born in Baby-Friendly hospitals with limited birth interventions (Bertini et al., 2015; Pounds \& Shostrom, 2018; Procaccini, Curley, \& Goldman, 2018) had lower mean weight loss, whereas a Baby-Friendly hospital with many cesareans and instrumental births documented more excessive weight loss (Castilho, Miranda, Fernandes, Cunha, \& Barroso, 2018). Infants born by cesarean section have a significantly higher weight loss and a delayed nadir (Fonseca, Severo, Barros, \& Santos, 2014; Flaherman et al., 2015) compared with those born in institutions with low or null cesarean rates (Crossland et al., 2008; Bertini et al., 2015). The difference in cesarean rates explains 


\begin{tabular}{|c|c|c|c|c|c|c|c|c|}
\hline \multirow[t]{2}{*}{ Author } & \multirow[t]{2}{*}{ Setting } & \multirow[t]{2}{*}{ Design } & \multirow[t]{2}{*}{ \# centers } & \multirow[t]{2}{*}{$\begin{array}{l}\mathrm{N} \text { of } \mathrm{BF} \\
\text { infants }\end{array}$} & \multirow[t]{2}{*}{ Cesarean births } & \multicolumn{2}{|c|}{ 50th percentile nadir } & \multirow[t]{2}{*}{ Comments } \\
\hline & & & & & & RWL & time & \\
\hline Crossland et al. (2008) & $\begin{array}{l}\text { Sunderland, } \\
\text { UK } \\
\end{array}$ & prospective & single & 111 & Data unavailable & $6,4 \% \pm 0.9 \%$ & $\begin{array}{l}\text { Approximately } \\
48 \mathrm{~h}\end{array}$ & \\
\hline $\begin{array}{l}\text { van Dommelen, Boer, } \\
\text { Unal, and van Wouwe } \\
\text { (2014) }\end{array}$ & Netherlands & retrospective & multicenter & 2359 & $\begin{array}{l}\text { Approximately } \\
10 \%\end{array}$ & $6.2 \%$ & $48 \mathrm{~h}$ & \\
\hline
\end{tabular}

Note. $\mathrm{RWL}=$ Relative weight loss; $\mathrm{BF}=$ Breastfeeding; $\mathrm{BM}=$ Breast milk; $\mathrm{WL}=$ Weight loss.

aPersonal communication.

${ }^{b}$ Nadir data for Flaherman et al. (2015) are taken from the percentile charts. 
Figure 1. Comparison of relative weight loss median curves for different authors (Bertini et al., 2015; Flaherman et al., 2015; Fonseca et al., 2015; van Dommelen et al., 2014).

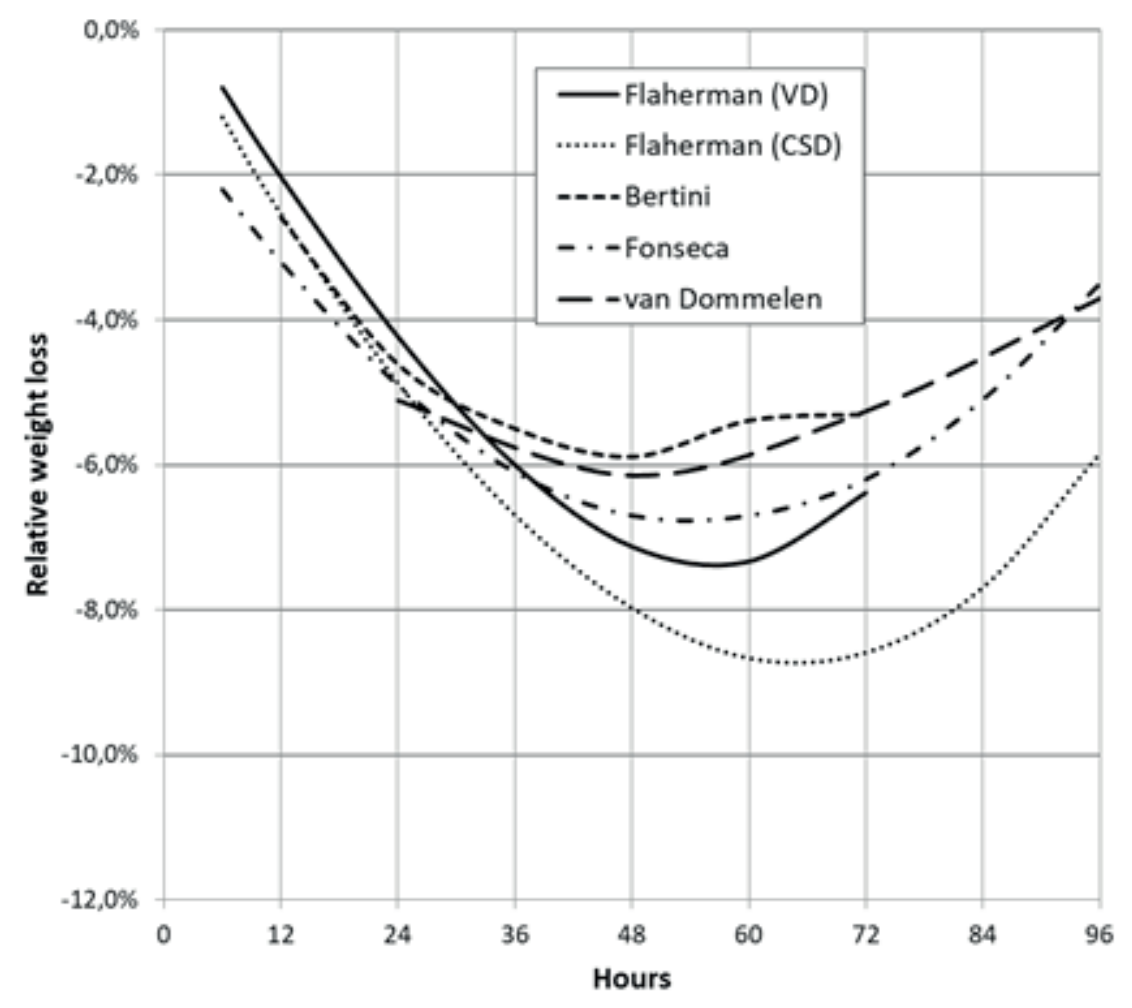

Note. $\mathrm{CSD}=$ cesarean section deliveries; $\mathrm{VD}=$ vaginal deliveries.

some of the variance in median weight loss in Figure 1: The cesarean rate in Fonseca et al. (2014) was 29\%, as contrasted with $0 \%$ in Bertini's cohort, and $10 \%$ in van Dommelen's. Mothers over 40 had about 2.4 times the risk of their infant losing excessive weight (Fonseca et al., 2014).

Results of the European cohorts reveal similar median weight loss (Bertini 5.9\%, van Dommelen 6.2\%, Fonseca $6.7 \%)$, in contrast to the value found by Flaherman et al. (2015) for vaginal deliveries in the United States (7.4\%), reflecting cultural differences in labor and postpartum practices. Indeed, a U.S. Centers for Disease Control report concluded that "Most U.S. hospitals have policies and practices that do not conform to international recommendations for best practices in maternity care and interfere with mothers' abilities to breastfeed." (Centers for Disease Control and Prevention [CDC], 2011). Epidural analgesia during labor was associated with increased newborn weight loss in a Canadian multihospital chart audit (Martens \& Romphf, 2007).
Cultural practices around breastfeeding initiation matter also, weight loss was much lower in Bosotho mothers (Tjon A Ten, Kusin, \& de With, 1986) who initiate breastfeeding in the first hour versus Ngiti and Bira (Enzunga \& Fischer, 1990) who delay breastfeeding. This is unsurprising. Bystrova and colleagues found a 54\% greater milk intake on day 4 in infants who initiated breastfeeding in the first 2 hours after birth versus those who started later in the first day of life (Bystrova, Bystrova et al., 2007).

Japanese women who initiated breastfeeding in the first 2 hours were more likely to be still breastfeeding at 4 months (Nakao, Moji, Honda, \& Oishi, 2008). Infants also lost more weight in the summer (Davanzo et al., 2013; Jain \& Basu, 2010; Shah \& Javadekar, 2018). With so many variables, it is unsurprising that a systematic review by Thulier (2017) found insufficient research to pin down normal weight loss in breastfed infants.

Differences in weight loss by population decrease markedly at the low end of the dataset (Figure 2). The 
Figure 2. Comparison of relative weight loss 90th percentile curves for different authors (Bertini et al., 2015; Flaherman et al., 2015; Fonseca et al., 2015; van Dommelen et al., 2014).

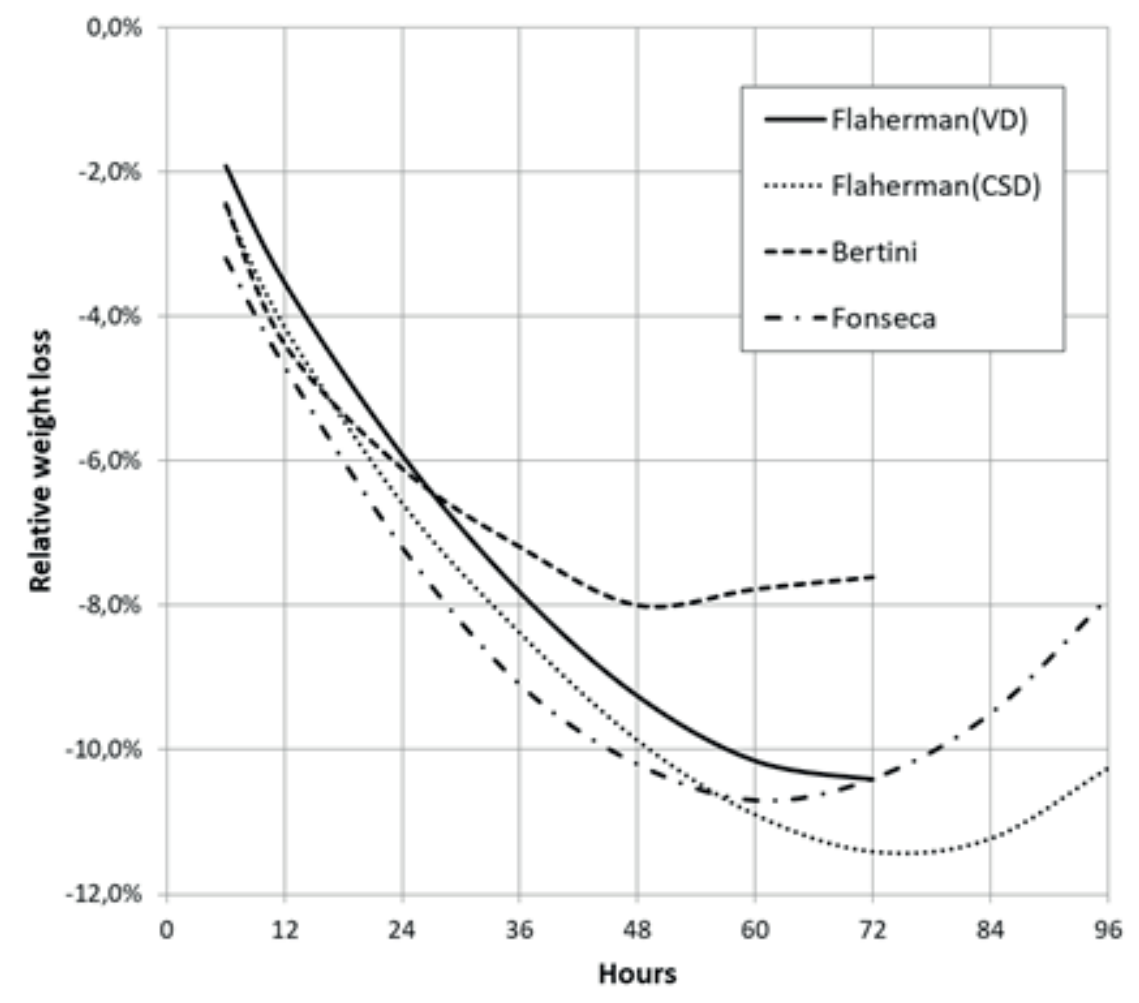

Note. $\mathrm{CSD}=$ cesarean section deliveries; $\mathrm{VD}=$ vaginal deliveries .

90th percentile of weight loss was unavailable for van Dommelen's data, as it was expressed in $z$ scores in their study. The striking difference is that in Bertini's study no infant lost $10 \%$ or more of birthweight, and the $90^{\text {th }}$ percentile nadir is $8 \%$; while the other studies all exceed $10 \%$. Births at the Centro Nascita Margherita are restricted to low-risk mothers and infants, births are all vaginal and unmedicated, conditions that according to the authors create a normative "standard" (Bertini et al., 2015).

van Dommelen et al. (2007) found no cases of hypernatremic dehydration before day 3 . Their data revealed that a $10 \%$ weight loss in the first week of life provided too many false negatives, whereas losing more than 2.5 standard deviations on their normal growth curve identified all infants at risk. Infants remaining 10\% below birth weight after 1 week were at high risk and should be hospitalized for biochemical tests and rehydration. Rapid rehydration during hypernatremic dehydration causes cerebral edema and increases the chance of poor outcomes (Boskabadi et al., 2017; Laing \& Wong, 2002; Lavagno et al., 2016). Continued provision of expressed breast milk (and breastfeeding, if the infant is able) is appropriate during rehydration. Previous concerns about sodium exposure from breast milk have proven unfounded when infants receive sufficient fluid volume (Laing \& Wong, 2002; Oddie, Richmond, \& Coulthard, 2001).

\section{Symptoms Indicating Low Intake}

Symptoms of dehydration or low breast milk intake should not be ignored at any age. Stool output in the first 5 days was negatively associated with weight loss in normal newborns (Shrago, Reifsnider, \& Insel, 2006). Differences in stooling patterns was not significantly different until after day 2 in infants later diagnosed with hypernatremic dehydration (DiTomasso \& Paiva, 2018; Thulier, 2017), by which time many U.S. infants are discharged. Fewer than three daily stools was almost universal before readmission for hypernatremic 
dehydration in an Indian retrospective review (Yaseen, Salem, \& Darwich, 2004).

Mothers and health-care providers need to understand the importance of normal stooling patterns in young breastfed infants (Livingstone, Willis, Abdel-Wareth, Thiessen, \& Lockitch, 2000). Health-care professional education is particularly important in cultures where breastfeeding rates have previously been low and mothers have little breastfeeding knowledge. First-time mothers, and those with low breastfeeding exposure and education, are consistently identified as more likely to experience unrecognized lactation failure. A comprehensive list of risk factors for hypernatremic dehydration appears in a systematic review by Lavagno and colleagues (Lavagno et al., 2016).

Signs of dehydration may be subtle in hypernatremic dehydration, as fluid is shifted to extracellular compartment by osmotic pressure from the elevated sodium (Neifert, 2001). Dry mucous membranes and/or fever were early signs of hypernatremic dehydration in a recent retrospective review (Ünver Korğalı, Cihan, Oğuzalp, Şahinbaş, \& Ekici, 2017); lethargy or hypotension in another (Konetzny et al., 2009). Irritability or inconsolable crying with constant ineffective feeding attempts should also be investigated with a high index of suspicion.

Takahashi and colleagues found that infants with excessive weight loss showed increased rooting intensity (Takahashi, Takahashi et al., 2015). An increased number of feedings with excessive weight loss is a marker for lactation failure "perhaps as an expression of thirst" (Marchini \& Stock, 1997). As the infant decompensates, the number of feeds may sharply decrease (Boskabadi et al., 2017). Jaundice is also common in underfed infants, starvation increases re-uptake of bilirubin through the enterohepatic circulation. In one retrospective review, $49 \%$ of hypernatremic infants were also jaundiced, and 65\% had cesarean births (Uras, Karadag, Dogan, Tonbul, \& Tatli, 2007).

\section{Recommendations}

Immediate or early skin-to-skin care is one evidencebased support for breastfeeding. A non-randomized trial showed that 120 minutes of skin-to-skin (S2S) contact initiated within 30 minutes of birth (vaginal, cesarean, or instrumental) was associated with about a five-fold greater odds of exclusive breastfeeding at 3 months versus no early skin-to-skin contact (Vila-Candel, Duke, Soriano-Vidal, \& Castro-Sánchez, 2018). Since low milk production or low infant weight gain were the most common reasons women gave for discontinuing breastfeeding before 3 months, and almost $60 \%$ of S2S dyads were still exclusively breastfeeding, it is probable that early, uninterrupted skin-to-skin care can reduce excessive newborn weight loss as well.

The data we found on infant weight changes highlighted the impact of perinatal practices including birth interventions and postpartum breastfeeding management. This is an obvious area for quality improvement in the Joint Commission perinatal core measure set.

We propose early assessment by IBCLCs of all dyads with higher than expected weight loss in the first 24 hours to ensure infant safety. If any signs of inadequate milk transfer or production are observed, manual expression and spoon feeding of colostrum can protect both maternal milk production and the infant's metabolic health. Other potential interventions flow from the findings of a thorough clinical breastfeeding assessment (Genna \& Sandora, 2016). We have provided a decision tree (see Appendix) to aid in these assessments.

\section{References}

Bertini, G., Breschi, R., \& Dani, C. (2015). Physiological weight loss chart helps to identify high-risk infants who need breastfeeding support. Acta Paediatrica, 104(10), 1024-1027. http://dx.doi. org/10.1111/apa.12820

Boskabadi, H., Akhondian, J., Afarideh, M., Maamouri, G., Bagheri, S., Parizadeh, S. M., . . Frens, G. A. (2017). Long-term neurodevelopmental outcome of neonates with hypernatremic dehydration. Breastfeeding Medicine, 12(3), 163-168. http://dx. doi.org/10.1089/bfm.2016.0054

Bystrova, K., Widström, A. M., Matthiesen, A. S., Ransjö-Arvidson, A. B., Welles-Nyström, B., Vorontsov, I., \& Uvnäs-Moberg, K. (2007). Early lactation performance in primiparous and multiparous women in relation to different maternity home practices. A randomised trial in St. Petersburg. International Breastfeeding Journal, 2(1), 9. http://dx.doi.org/10.1186/17464358-2-9

Castilho, S., Miranda, A. M., Fernandes, C. A., Cunha, M., \& Barroso, R. (2018). Excess weight loss and hypernatremia in exclusively breastfed infants. Journal of Pediatric and Neonatal Individualized Medicine, 7(2), e070212.

Centers for Disease Control and Prevention [CDC]. (2011). Vital signs: hospital practices to support breastfeeding-United States, 2007 and 2009. MMWR. Morbidity and mortality weekly report, 60(30), 1020

Chantry, C. J., Dewey, K. G., Peerson, J. M., Wagner, E. A., \& Nommsen-Rivers, L. A. (2014). In-hospital formula use increases early breastfeeding cessation among first-time mothers intending to exclusively breastfeed. The Journal of Pediatrics, 164(6), 1339-1345. http://dx.doi.org/10.1016/j.jpeds.2013.12.035

Crossland, D. S., Richmond, S., Hudson, M., Smith, K., \& AbuHarb, M. (2008). Weight change in the term baby in the first 
2 weeks of life. Acta Paediatrica, 97(4), 425-429. http://dx.doi. org/10.1111/j.1651-2227.2008.00685.x

Davanzo, R., Cannioto, Z., Ronfani, L., Monasta, L., \& Demarini, S. (2013). Breastfeeding and neonatal weight loss in healthy term infants. Journal of Human Lactation, 29(1), 45-53. http:// dx.doi.org/10.1177/0890334412444005

DeMarzo, S., Seacat, J., \& Neifert, M. (1991). Initial weight loss and return to birth weight criteria for breast-fed infants: challenging the 'rule of thumb'. Am J Dis Children, 145, 402.

Deng, X., \& McLaren, M. (2018). Using 24-Hour Weight as Reference for Weight Loss Calculation Reduces Supplementation and Promotes Exclusive Breastfeeding in Infants Born by Cesarean Section. Breastfeeding Medicine, 13(2), 128-134. http://dx.doi.org/10.1089/bfm.2017.0124

Dewey, K. G., Nommsen-Rivers, L. A., Heinig, M. J., \& Cohen, R. J. (2003). Risk factors for suboptimal infant breastfeeding behavior, delayed onset of lactation, and excess neonatal weight loss. Pediatrics, 112(3 Pt 1), 607-619. http://dx.doi.org/10.1542/ peds.112.3.607

DiTomasso, D., \& Paiva, A. L. (2018). Neonatal weight matters: An examination of weight changes in full-term breastfeeding newborns during the first 2 weeks of life. Journal of Human Lactation, 34(1), 86-92. http://dx.doi.org/10.1177/ $\underline{0890334417722508}$

Enzunga, A., \& Fischer, P. R. (1990). Neonatal weight loss in rural Zaire. Annals of Tropical Paediatrics, 10(2), 159-163. http://dx. doi.org/10.1080/02724936.1990.11747424

Flaherman, V. J., Kuzniewicz, M. W., Li, S., Walsh, E., McCulloch, C. E., \& Newman, T. B. (2013). First-day weight loss predicts eventual weight nadir for breastfeeding newborns. Archives of Disease in Childhood - Fetal and Neonatal Edition, 98(6), F488F492. http://dx.doi.org/10.1136/archdischild-2012-303076

Flaherman, V. J., Schaefer, E. W., Kuzniewicz, M. W., Li, S. X., Walsh, E. M., \& Paul, I. M. (2015). Early weight loss nomograms for exclusively breastfed newborns. Pediatrics, 135(1), e16-e23. http://dx.doi.org/10.1542/peds.2014-1532

Flaherman, V. J., Schaefer, E. W., Kuzniewicz, M. K., Li, S., Walsh, E., \& Paul, I. M. (2017). Newborn weight loss during birth hospitalization and breastfeeding outcomes through age 1 month. Journal of Human Lactation, 33(1), 225-230. http://dx. doi.org/10.1177/0890334416680181

Fonseca, M. J., Severo, M., Barros, H., \& Santos, A. C. (2014). Determinants of weight changes during the first 96 hours of life in full-term newborns. Birth, 41(2), 160-168. http://dx.doi.org/ $\underline{10.1111 / \text { birt. } 12087}$

Fonseca, M. J., Severo, M., \& Santos, A. C. (2015). A new approach to estimating weight change and its reference intervals during the first 96 hours of life. Acta Paediatrica, 104(10), 1028-1034. http://dx.doi.org/10.1111/apa.12894

Genna, C. W., \& Sandora, L. (2016). Normal Sucking and Swallowing in Genna, CW Supporting Sucking Skills in Breastfeeding Infants (3 ${ }^{\text {rd }}$ edition). Burlington, MA: Jones and Bartlett Learning.

Grossman, X., Chaudhuri, J. H., Feldman-Winter, L., \& Merewood, A. (2012). Neonatal weight loss at a US Baby-Friendly Hospital. Journal of the Academy of Nutrition and Dietetics, 112(3), 410-413. http://dx.doi.org/10.1016/i.jada.2011.10.024
Iyer, N. P., Srinivasan, R., Evans, K., Ward, L., Cheung, W. Y., \& Matthes, J. W. (2008). Impact of an early weighing policy on neonatal hypernatraemic dehydration and breast feeding. Archives of Disease in Childhood, 93(4), 297-299. http://dx.doi. org/10.1136/adc.2006.108415

Jain, S., \& Basu, S. (2010). Hypernatremic dehydration in term and near-term neonates. The Indian Journal of Pediatrics, 77(4), 461-461. http://dx.doi.org/10.1007/s12098-009-0301-0

Konetzny, G., Bucher, H. U., \& Arlettaz, R. (2009). Prevention of hypernatraemic dehydration in breastfed newborn infants by daily weighing. European Journal of Pediatrics, 168(7), 815-818. http://dx.doi.org/10.1007/s00431-008-0841-8

Laing, I. A., \& Wong, C. M. (2002). Hypernatraemia in the first few days: is the incidence rising? Archives of Disease in Childhood - Fetal and Neonatal Edition, 87(3), 158F-162. http://dx.doi.org/ $\underline{10.1136 / \mathrm{fn} \cdot 87 \cdot 3 \cdot \mathrm{F} 158}$

Lavagno, C., Camozzi, P., Renzi, S., Lava, S. A., Simonetti, G. D., Bianchetti, M. G., \& Milani, G. P. (2016). Breastfeedingassociated hypernatremia: a systematic review of the literature. Journal of human lactation: official journal of International Lactation Consultant Association, 32(1), 67-74. http://dx.doi.org/10.1177/ $\underline{0890334415613079}$

Livingstone, V. H., Willis, C. E., Abdel-Wareth, L. O., Thiessen, P., \& Lockitch, G. (2000). Neonatal hypernatremic dehydration associated with breast-feeding malnutrition: a retrospective survey. CMAJ : Canadian Medical Association journal = journal de l'Association medicale canadienne, 162(5), 647-652.

Macdonald, P. D., Ross, S. R., Grant, L., \& Young, D. (2003). Neonatal weight loss in breast and formula fed infants. Archives of Disease in Childhood - Fetal and Neonatal Edition, 88(6), 472F-476. http://dx.doi.org/10.1136/fn.88.6.F472

Manganaro, R., Mamì, C., Marrone, T., Marseglia, L., \& Gemelli, M. (2001). Incidence of dehydration and hypernatremia in exclusively breast-fed infants. The Journal of Pediatrics, 139(5), 673-675. http://dx.doi.org/10.1067/mpd.2001.118880

Marchini, G., \& Stock, S. (1997). Thirst and vasopressin secretion counteract dehydration in newborn infants. The Journal of Pediatrics, 130(5), 736-739. http://dx.doi.org/10.1016/S00223476(97)80015-7

Martens, P. J., \& Romphf, L. (2007). Factors associated with newborn in-hospital weight loss: comparisons by feeding method, demographics, and birthing procedures. Journal of Human Lactation, 23(3), 233-241. http://dx.doi.org/10.1177/ $\underline{0890334407303888}$

Mulder, P. J., \& Gardner, S. E. (2015). The healthy newborn hydration model: A new model for understanding newborn hydration immediately after birth. Biological research for nursing, 17(1), 94-99. http://dx.doi.org/10.1177/1099800414529362

Mulder, P. J., Johnson, T. S., \& Baker, L. C. (2010). Excessive weight loss in breastfed infants during the postpartum hospitalization. Journal of Obstetric, Gynecologic $\mathcal{E}$ Neonatal Nursing, 39(1), 15-26. $\underline{\text { http://dx.doi.org/10.1111/i.1552-6909.2009.01085.x }}$

Nakao, Y., Moji, K., Honda, S., \& Oishi, K. (2008). Initiation of breastfeeding within 120 minutes after birth is associated with breastfeeding at four months among Japanese women: a selfadministered questionnaire survey. International Breastfeeding Journal, 3(1), 1. 
Neifert, M. R. (2001). Prevention of breastfeeding tragedies. Pediatric Clinics of North America, 48(2), 273-297. http://dx.doi.org/10. 1016/S0031-3955(08)70026-9

Neville, M. C., Keller, R., Seacat, J., Lutes, V., Neifert, M., Casey, C., . . . Archer, P. (1988). Studies in human lactation: milk volumes in lactating women during the onset of lactation and full lactation. The American Journal of Clinical Nutrition, 48(6), 1375-1386. http://dx.doi.org/10.1093/ajcn/48.6.1375

Noel-Weiss, J., Courant, G., \& Woodend, A. K. (2008). Physiological weight loss in the breastfed neonate: a systematic review. Open Medicine: A Peer-Reviewed, Independent, Open-Access Journal, 2(4), e99.

Noel-Weiss, J., Woodend, A. K., Peterson, W. E., Gibb, W., \& Groll, D. L. (2011). An observational study of associations among maternal fluids during parturition, neonatal output, and breastfed newborn weight loss. International Breastfeeding Journal, 6(1), 9. http://dx.doi.org/10.1186/1746-4358-6-9

Oddie, S., Richmond, S., \& Coulthard, M. (2001). Hypernatraemic dehydration and breast feeding: a population study. Archives of Disease in Childhood, 85(4), 318-320. http://dx.doi.org/10.1136/ adc.85.4.318

Pounds, L., \& Shostrom, V. (2018). Analyzing Factors That Impact Breastfeeding Duration in the Postpartum Period: A Secondary Analysis of PRAMS Data. Breastfeeding Medicine, 13(5), 335-340. http://dx.doi.org/10.1089/bfm.2018.0020

Procaccini, D., Curley, A. L. C., \& Goldman, M. (2018). BabyFriendly Practices Minimize Newborn Infants Weight Loss. Breastfeeding Medicine, 13(3), 189-194. http://dx.doi.org/10. $1089 / \mathrm{bfm} .2017 .0182$

Shah, R. H., \& Javadekar, B. B. (2018). Clinical profile and outcome of neonates admitted during summer months with dehydration and hypernatremia in tertiary care hospital of central Gujarat, India. International Journal of Contemporary Pediatrics, 5(3), 761-763. http://dx.doi.org/10.18203/2349. 3291.ijcp20181063

Shrago, L. C., Reifsnider, E., \& Insel, K. (2006). The Neonatal Bowel Output Study: indicators of adequate breast milk intake in neonates. Pediatric nursing, 32(3), 195-201.

Takahashi, Y., Jonas, W., Ransjö-Arvidson, A. B., Lidfors, L., Uvnäs Moberg, K., \& Nissen, E. (2015). Weight loss and low age are associated with intensity of rooting behaviours in newborn infants. Acta Paediatrica, 104(10), 1018-1023. http://dx.doi.org/ 10.1111/apa.13077

Tawia, S., \& McGuire, L. (2014). Early weight loss and weight gain in healthy, full-term, exclusively-breastfed infants. Breastfeeding rReview: Professional Publication of the Nursing Mothers' Association of Australia, 22(1), 31.

Thulier, D. (2017). Challenging expected patterns of weight loss in full-term breastfeeding neonates born by Cesarean. Journal of
Obstetric, Gynecologic EO Neonatal Nursing, 46(1), 18-28. http:// dx.doi.org/10.1016/j.jogn.2016.11.006

Timmerman, H. M., Rutten, N., Boekhorst, J., Saulnier, D. M., Kortman, G. A. M., Contractor, N., . . Rijkers, G. T, Kleerebezem, M. (2017). Intestinal colonisation patterns in breastfed and formula-fed infants during the first 12 weeks of life reveal sequential microbiota signatures. Scientific Reports, 7(1), 8327. http://dx.doi.org/10.1038/s41598-017-08268-4

Tjon A Ten, W. E., Kusin, J. A., \& de With, C. (1986). Early postnatal growth of Basotho infants in the Mantsonyane area, Lesotho. Annals of tropical paediatrics, 6(3), 195-198.

Uras, N., Karadag, A., Dogan, G., Tonbul, A., \& Tatli, M. M. (2007). Moderate hypernatremic dehydration in newborn infants: retrospective evaluation of 64 cases. The Journal of Maternal-Fetal Eु Neonatal Medicine, 20(6), 449-452. http://dx. doi.org/10.1080/14767050701398256

van Dommelen, P., Boer, S., Unal, S., \& van Wouwe, J. P. (2014). Charts for weight loss to detect hypernatremic dehydration and prevent formula supplementing. Birth, 41(2), 153-159. http:// dx.doi.org/10.1111/birt.12105

van Dommelen, P., van Wouwe, J. P., Breuning-Boers, J. M., van Buuren, S., \& Verkerk, P. H. (2007). Reference chart for relative weight change to detect hypernatraemic dehydration. Archives of Disease in Childhood, 92(6), 490-494. http://dx.doi.org/10. 1136/adc.2006.104331

Verd, S., de Sotto, D., Fernández, C., \& Gutiérrez, A. (2018). Impact of in-hospital birth weight loss on short and medium term breastfeeding outcomes. International Breastfeeding Journal, 13(1), 25. http://dx.doi.org/10.1186/s13006-018$\underline{0169-6}$

Vila-Candel, R., Duke, K., Soriano-Vidal, F. J., \& Castro-Sánchez, E. (2018). Affect of Early Skin-to-Skin Mother-Infant Contact in the Maintenance of Exclusive Breastfeeding: Experience in a Health Department in Spain. Journal of Human Lactation, 34(2), 304-312. http://dx.doi.org/10.1177/0890334416676469

Wilbaux, M., Kasser, S., Wellmann, S., Lapaire, O., van den Anker, J. N., \& Pfister, M. (2016). Characterizing and forecasting individual weight changes in term neonates. The Journal of Pediatrics, 173, 101-107. http://dx.doi.org/10.1016/j.jpeds.2016. $\underline{02.044}$

Yaseen, H., Salem, M., \& Darwich, M. (2004). Clinical presentation of hypernatremic dehydration in exclusively breast-fed neonates. The Indian Journal of Pediatrics, 71(12), 1059-1062. http://dx.doi. org/10.1007/BF02829814

Ünver Korğalı, E., Cihan, M. K., Oğuzalp, T., Şahinbaş, A., \& Ekici, M. (2017). Hypernatremic dehydration in breastfed term infants: Retrospective evaluation of 159 cases. Breastfeeding Medicine, 12(1), 5-11. http://dx.doi.org/10.1089/bfm.2016. $\underline{0077}$ 

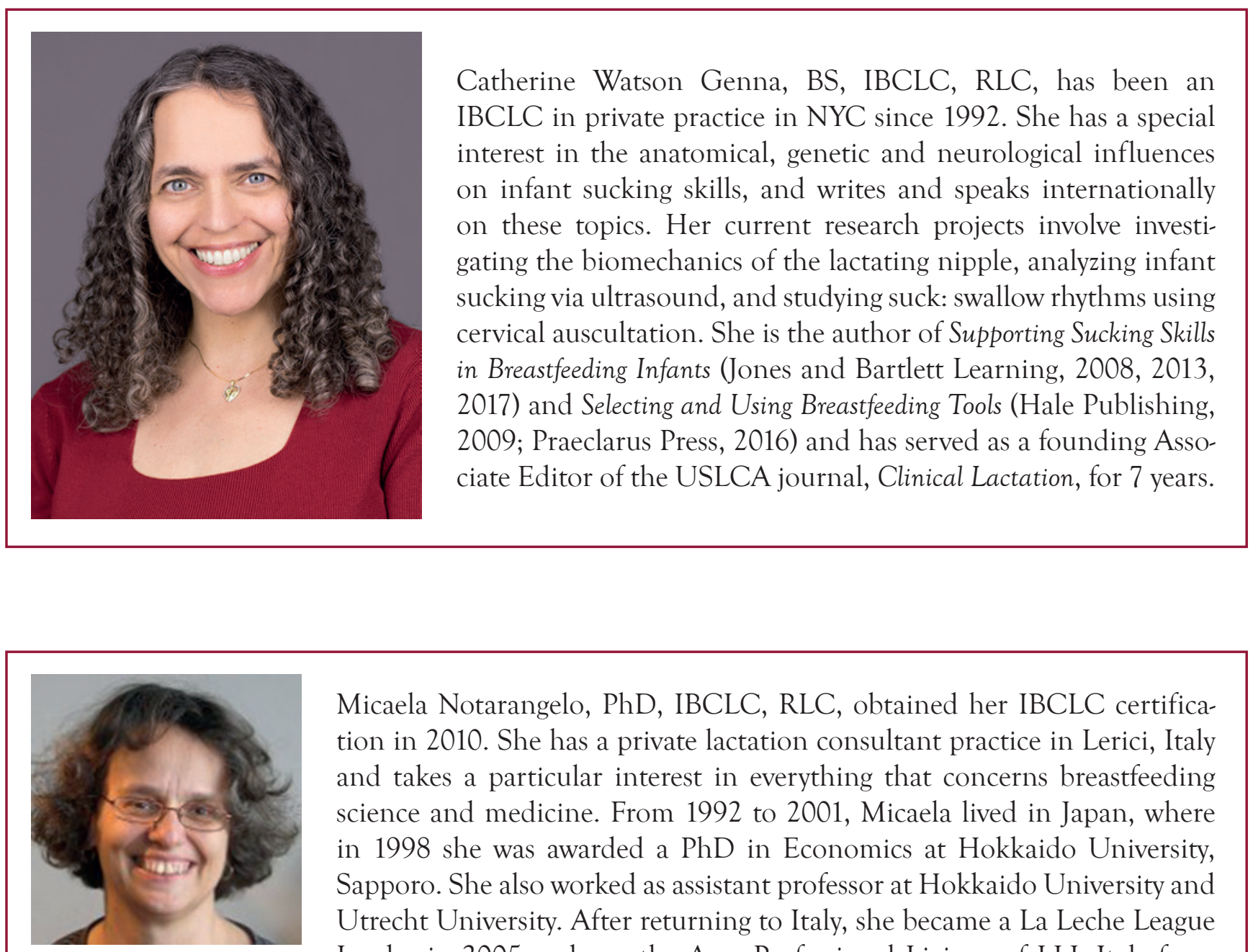

Micaela Notarangelo, PhD, IBCLC, RLC, obtained her IBCLC certification in 2010. She has a private lactation consultant practice in Lerici, Italy and takes a particular interest in everything that concerns breastfeeding science and medicine. From 1992 to 2001, Micaela lived in Japan, where in 1998 she was awarded a $\mathrm{PhD}$ in Economics at Hokkaido University, Sapporo. She also worked as assistant professor at Hokkaido University and Utrecht University. After returning to Italy, she became a La Leche League Leader in 2005 and was the Area Professional Liaison of LLL Italy from 2010 to 2013. Since 2013, she has been serving in the Board of Directors of IBLCE. In 2017, together with Chiara Toti, IBCLC, Micaela has developed a new two-day course for health care providers about breastfeeding support for babies with lip and/or palate cleft. The course has been held, with the financial support of Aismel, a parents' association, in several major Italian hospitals and has been met with great appraisal. 


\section{APPENDIX}

\section{Decision Tree}

\section{Causes of WL}

Interventions

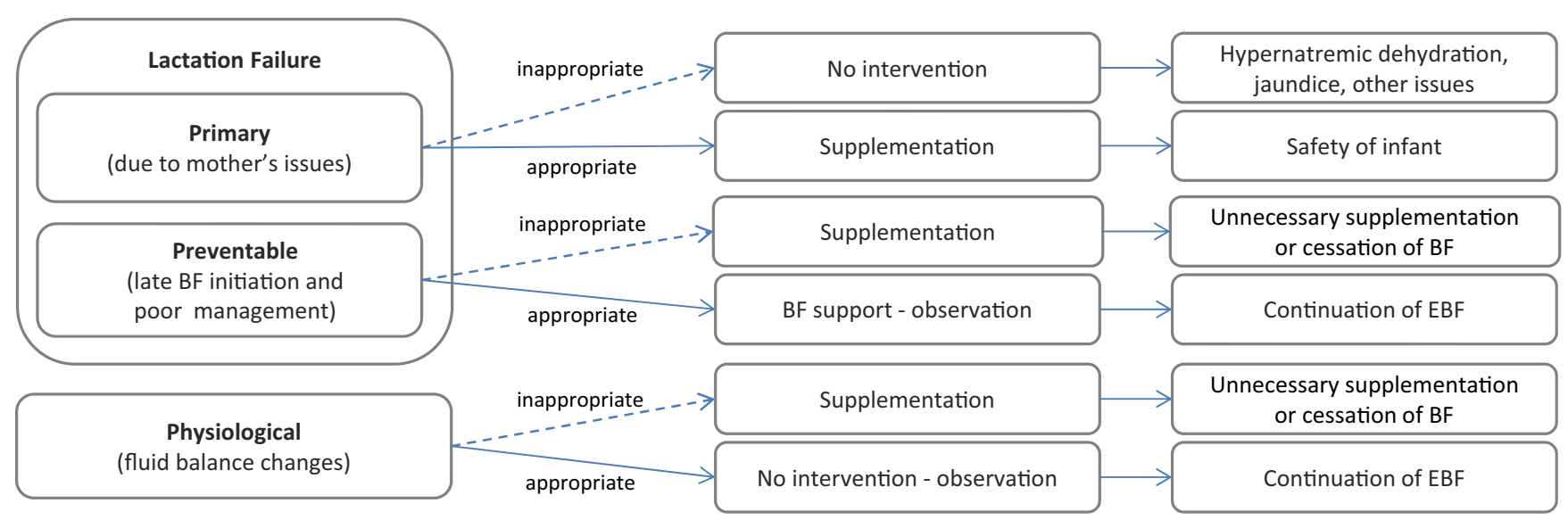

Note. $\mathrm{BF}=$ breastfeeding; $\mathrm{EBF}=$ exclusive breastfeeding; $\mathrm{WL}=$ weight loss. 